\title{
Biochemical characteristics of distal vessels endothelium in patients with syndroms of lumbosacral radiculopathies and others neurological syndromes lumbar osteochondrosis in recrudescence phase
}

\author{
Marina Goryacheva ${ }^{1,2, ~ *, ~ G r i g o r i ~ S h u m a k h e r ², ~ L i l i y a ~ K o s t y u c h e n k o ~}{ }^{3}$, Larisa Tsybirova2, \\ Peter Veselovsky², Sergey Fedyanin ${ }^{2}$, Alexey Malikov², Oleg Komarov ${ }^{2}$, Andrey Belousov ${ }^{4}$, \\ Maria Bondareva ${ }^{2}$, Ksenia Goryacheva ${ }^{2}$ \\ ${ }^{1}$ Chair of Biology of Altai State Medical University of RF Public Health Care Ministry, Barnaul, Russia \\ ${ }^{2}$ Chair of Nervous Diseases delivering the course of neurology with the framework of Refresher Courses and Continuing Education of \\ Specialists at Altai State Medical University of RF Public Health Care Ministry, Barnaul, Russia \\ ${ }^{3}$ Chair of Therapy delivering the course of Immunology at Altai State University of RF Public Health Care Ministry, Barnaul, Russia \\ ${ }^{4}$ Central Scientific-Research Laboratory at Altai State Medical University of RF Public Health Care Ministry, Barnaul, Russia
}

\section{Email address:}

goryachevamarina@mail.ru (M. Goryacheva),prof064@mail.ru (G. Shumakher), lilya.kostyuchenko@mail.ru (L. Kostyuchenko), ltsibirova@mail.ru (L. Tsybirova), petrveselovskii@gmail.com (P. Veselovsky), fedsa@bk.ru (S. Fedyanin), malikov.as@mail.ru (A. Malikov), kopi777@mail.ru(O. Komarov), belousov@agmu.ru (A. Belousov), maryvrach@gmail.com (M. Bondareva),ksenia.goryacheva@gmail.com (K. Goryacheva)

\section{To cite this article:}

Marina Goryacheva, Grigori Shumakher, Liliya Kostyuchenko, Larisa Tsybirova, Peter Veselovsky, Sergey Fedyanin, Alexey Malikov, Oleg Komarov, Andrey Belousov, Maria Bondareva, Ksenia Goryacheva. Biochemical Characteristics of Distal Vessels Endothelium in Patients with Syndroms of Lumbosacral Radiculopathies and others Neurological Syndromes Lumbar Osteochondrosis in Recrudescence Phase. Advances in Biochemistry. Vol. 2, No. 6, 2014, pp. 95-102. doi: 10.11648/j.ab.20140206.13

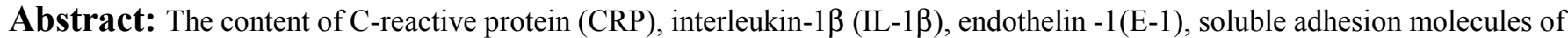
vascular endothelium-1 (sVCAM-1) and soluble molecules of intercellular adhesion -1 (sICAM-1 ) in peripheral blood of patients suffering from neurologic syndromes of dorsolumbar osteochondrosis (lumbalgia, lumboishialgia, lumbosacral radiculupathy) in recrudescence phase was investigated. CRP concentration in blood serum was determined by highly sensitive quantitative method (hs-CRP), based on the reaction of immunoprecipitation with reagent sets "Thermoscientific" firm, USA.

Endothelin-1, sVCAM-1, sICAM-1 content in blood serum was determined by means of immunoenzymometric analysis method. The research was carried out with standard diagnostic reagent set of the "BioMedica", "Bender MedSystem»" (BMS201, BMS 232) firm, (Austria), and the apparatus "Multiscan" of the Labsystem firm (Finland). Statistically significant $(\mathrm{p}<0,05)$ concentration increase of C-reactive protein, interleukin-1 $\beta$ (IL-1 $\beta$ ), endothelin -1, sVCAM-1 and sICAM-1 in peripheral blood serum in patients having lumbosacral radiculopathy in comparison with the test-group and with groups of patients suffering from syndromes of lumbalgia and lumboishialgia was found out.
\end{abstract}

Keywords: C-Reactive Protein (hs-CRP), Interleukin-1 $\beta$ (IL-1 $\beta$ ), Endothelin - 1 (E-1), Lumbosacral Radiculopathies, Soluble Adhesion Molecules of Vascular Endothelium - 1 (sVCAM-1), Lumbalgia (Lumbodynia), Soluble Molecules of Intercellular Adhesion - 1 (sICAM-1), Lumboishialgia

\section{Introduction}

According to WHO the most common causes of life quality worsening limitation of physical activity resulting in temporary incapacity for work and even to invalidity, are dorsalgias $[1,2]$. As a rule they require a long-term treatment and complex rehabilitation. The main and chief reason of "Low Back and Neck Pain" is, to present day knowledge, vertebral osteochondrosis $[3,4,5$,].

In the 60-70s of the XX century the founders of vertebroneurology: Ya.Yu. Popelyansky, V.P. Veselovsky, 
O.J.Kogan, I.R. Shmidt determined vertebral osteochondrosis as a multifactor disease with genetic predilection, characterized by degenerative-dystrophic changes in intervertebral disks and contiguous tissues with the secondary involvement of peripheral and central nervous system [6].

Pathogenetic mechanisms of the dorsalgias formation are related to vertebrogenic disorders of peripheral nervous system at the lumbar sacral osteochondrosis (LSO) - one of degenerative-dystrophic spine diseases (DDSD), - caused by irritation of synuvertebral nerve endings or compression of spinal cord nerve root due to structural dystrophic changes of spinal motion segment (SMS) [6,7-10].

LSO neurological syndromes are divided into vertebral and extravertebral. Vertebral syndromes only the damaged SMS and are expressed affect as musculotonic reactions in the damaged segment region in response to synuvertebral nerve irration. On lumbar level they are lumbago and lumbodynia. Extravertebral syndromes - lumbar ischialgia, lumbar-sacral radiculopathy (LSR) are formed on the background of vertebral syndrome, but show themselves out of the spine $[9,11,12]$. LSO neurological syndromes, in present day classification, are usually divided into reflexory-pain (lumbago, lumbodynia, lumbar ischialqia) and root syndromes $[8,10,11]$. Syndromes with more than 2 weeks duration: lumbodynia, lumbar ischialqia and radiculopathy - are the most wide-spread among spondylogenic neurological disorders $[9,13]$.

Choosing the tactics of LSO neurological syndromes treatment it is necessary to take into account either clinical or pathogenetic differences of LSO syndromes [14, 15]. But in many cases exact differential diagnostics of LSO neurological syndromes is rather complicated, as far as every of them represents an intricate complex of symptoms and at the same time all LSO neurological syndromes have a great number of mutual symptoms. The diagnostics is more difficult because of polyethiology and plurality of pathogenesis mechanisms: various types of LSO degenerative-distrophic damages, various basic mechanisms of peripheral nerve disorders: compressive, vascular, autoimmune - inflammable and so on $[13,16,17]$.

Differential diagnostics of reflexory pain syndromes (lumbodynia and lumbar ischialgia) and of lumbar-sacral radiculopathy (LSR) is of special importance.

LSR accounts for $70 \%[13,15]$ of disorders of peripheral nervous system and for $37,4 \%$ of spine degenerative-dystrophic diseases [13], and exactly these disorders causes a long term incapacity for work and inability.

All the above - mentioned problems need additional diagnostic criteria to be found out for differential diagnostics of LSO neurological syndromes in recrudescence stage.

At present the notion of pathogenesis of LSO extravertebral syndromes is gradually changing. For a long time LSO has been considered a local process, limited to one or several spinal motion segments (SMS); now the opinion is changing and LSO is believed to be a system pathology process, comprising skeleton-muscle-arthrosis system, vascular and immune systems and involving central regulation mechanisms $[7,15]$.

Peripheral vascular disorders like ischemia hemodynamic disturbances and microcirculation help to show vegetative-vascular, reactive-inflammable, stagnant and other reactions in clinic picture of radiculopathy $[11,12,9,13,17]$.

Neurovascular disorders are important and obligatory clinic demonstration of lumbar sacral radiculopathy (LSR) development. According to the classification of V.P. Veselovsky (1991), depending on dominating vascular disorders they are divided into arterial venous and mixed [7, 12].

In all cases the ischemic component was one of the main mechanisms of vascular disfunction, leading to the formation of compression-ischemic radiculopathy in lumbar section. According to Khabirov F.A. (2001), V.V. Belyakov, A.B. Sittel et al. (2002), one of the reasons of radiculopathy of lumbar-sacral section may be spondylogenic compression of epidural venous plexuses with the development of venous stasis (especially in the space of dural venouses and in place of root penetration through scleromeninx), which brings to its ischemia due to the spasm of feeling vessels $[10,16]$. Other possible mechanisms of compression neuropathy formation is the compression and ischemia of the nerve that comes across the muscle affected by spasm [7, 10, 18, 19]. These disorders are developing on the background of reactive inflammable processes, reaction of cellular and humoral immunity appearing in the range of dystrophically changed intervertebral disk [10, 13, 20, 21].

So, the obtained data speak for the fact, that only LSR are accompanied by local inflammatory, vascular-reactive, immune processes, that is not observed with other LSO syndromes $[15,17]$.

Nevertheless, taking into account serious condition of a patient under LSR recrudescence it can be hardly supposed that the processes are of strict local character and do not affect general hemodynamics (vascular system on the whole), and are not the signs of a system inflammatory process. But the notions of mechanisms of pathology process formation under LSR with peripheral vascular disorders involved are not supported by the data on the intima of peripheral vessels.

The confirmation of peripheral vascular disorders as the most important ethiological and pathogentic component under LSR may become detection of markers of inflammation and disfunction of vascular endothelin in peripheral blood stream under this pathology.

The aim of the given investigation was to detect interrelation of a system inflammatory process and vascular disfunction in formation of LSP and others neurological syndromes of lumbar osteochondrosis in recrudescence stage.

\section{Material and Methods}

The investigation was carried out on the basic of neurology department of Clinical Hospital of Barnaul Railway Station, Barnaul of Altai District, Russia. The conditions agreed to the 
demands of "WMA Declaration of Helsinki - Ethical Principles for Medical Research Involving Human Subject" with amendments of 2000 . All patients have signed written informed consents.

352 patients took part the investigation, they were divided into four main groups. Among the examined patients there were 300 cases with deferent neurological syndromes of lumbar osteochondrosis in recrudescence period.

There were $65 \%$ (195) men and $35 \%$ (105) women. The age ranged from 20 to 55 . The mean age was $41,1 \pm 9,7$. The examinees were divided into three groups: 75 with lumbodynia syndrome - group 1; 75 patients with lumbar ischialgia syndrome - group 2; in group 3 there were patients with lumbar sacral radiculopathy - 150 subjects - with various localization of root damage of spinal cord nerves. Among them the compression of the nerve root L4 was identified in 6 patients (4\%), L5 - in $26(17 \%), \mathrm{S} 1$ - in 52 patients $(35 \%)$, biradicular syndrome (L5, S1) was detected in 66 patients (44\%).

All the patients underwent routine neurological and vertebroneurological examination according to the techniques by Y.Yu. Popelyansky and F.A. Khabirov [6, 8, 10]. Additional techniques included: classical $\mathrm{x}$-ray study of lumbar-sacral region of spine, CI/MRI of lumbar spine region.

The results of 52 healthy subjects without neurological signs of lumbar-sacral osteochondrosis served as the control; the patients were comparable in age and sex with main groups.

Criteria for being excluded from the control and investigation groups were the following diseases: IHD, hypertensive disease, hyperlipidemia of various genesis, accelerated ESR syndrome, diseases of lower limbs vessels, chronic infectious and viral and autoimmune diseases, inflammatory arthrosis diseases of a different etiology, diseases of YII- and ENT-organic in recrudescence phase. Therefore all the patients underwent clinical biochemical examination: clinical blood and urine analysis, blood chemistry with fibrinogen and prothrombin index determination, lipidic blood spectrum, ECY, duplex of lower limbs vessels; the examinees were consulted by a therapeutist.

Concentration of CRP (hs-CRP) in blood serum was determined by extremely sensitive quantitative method (in the interval from $0.1 \mathrm{~g} / \mathrm{l})$, based on the reaction of immunoprecipitation with latex strengthening, using reagent sets ("Thermoscientific" firm, USA). Concentration of IL-1 $\beta$ was determined by enzyme-linked immunosorbent method, using standard reagent sets ("Bender Med System 224/2" firm, Austria), in accordance with the instructions. Gauging curve, plotted on IL-1 $\beta$ standards, in all the interval of investigated values, had a linear character.

Endothelin-1 concentration in blood serum was determined with enzyme-linked immunosorbent assay method. A standard set of reagents of "BioMedica" firm (Austria) was used.

sICAM-1 and sVCAM-1 concentration in blood serum was determined with enzyme-linked immunosorbent method with the help of commercial sets ("Bender MedSystem", Austria (BMS201, BMS232)), used for purposes of research only.

For all biomarkers investigated the concentration of samples being determined were in the range of sensitivity, recommended for identifying in standard sets.

Statistical analysis of the data obtained was performed using nonparametric methods (after checking up the normality of distribution of the found values). Mean values differences of quantitative intergroup parameters were determined wits the Mann-Whitney $U$ test for values, disconnected by pairs. Correlation analysis was made with Spearman's rank correlation method. The results are shown graphically as histograms or in the table in the form of corresponding median (M) value for each investigated groups, standard declination (SD) for each event is pointed out. The criterion of statistical accuracy of the obtained results was considered the value $\mathrm{p}<$ 0.05 , commonly used in medicine. Statistical analysis was performed on SPSS.

\section{Results and Discussion}

We determined the content of hs-CRP, IL-1 $1 \beta$, endothelin-1, soluble molecules of adhesion: of vascular endothelium-1 (sVCAM-1) and molecules of intercellular adhesion (sICAM-1) in peripheral blood of patients with neurological syndromes of lumbar sacral osteochondrosis (lumbodynia, lumbar ischialgia, lumbar sacral radiculopathy) on the background of tough criteria of excluding accompanying vascular malformation.

hs-CRP concentrations in blood serum of the examined patients are shown in Figure 1.

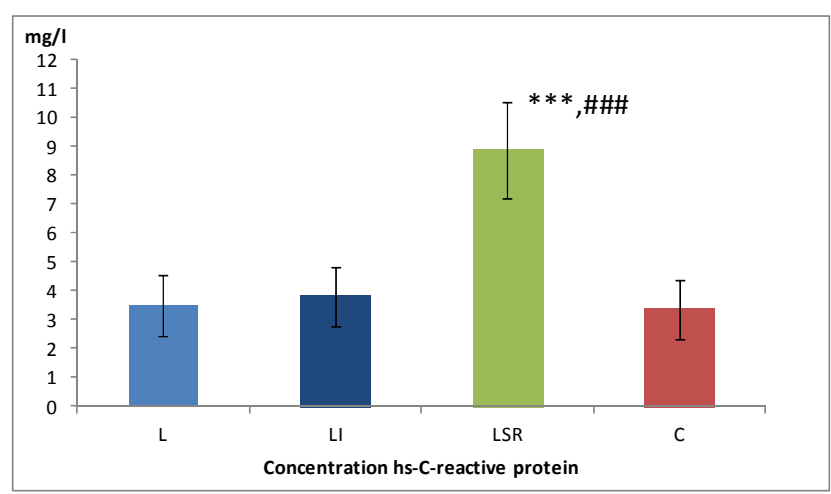

Figure 1. Concentration hs-C-reactive Protein ( $\mathrm{mg} / \mathrm{l})$ in Blood serum.

$\mathrm{C}-$ control (IV group), ( $\mathrm{n}=52)$;

$\mathrm{L}$ - patients with lumbodynia syndrome (I group), $(\mathrm{n}=75)$;

LI - patients with lumbar ischialqia syndromes (II group), $(n=75)$;

LSR-patients with lumbar-sacral radiculopathy syndromes (III group), $(\mathrm{n}=150)$;

Difference are significant between the group of patients with LSR syndromes and the control, $(* * *-\mathrm{p}<0,001)$.

Difference are significant the group of patients with LSR syndromes and other groups, (\#\#\#- p <0,001).

So, we can conclude that mean concentration values of CRP in all groups of the examined did not exceed normal ones $(10-11 \mathrm{mg} / \mathrm{l})$. But taking into consideration the purpose, we used highly sensitive quantitative method of CRP concentration determination, that enabled to detect differences in hs-CRP content in blood serum in the range of low CRP concentrations (less than 10-11 mg/l) on subclinical 
level. According to current knowledge, under the absence of system pathological processes, connected with tissue damage, infectious and autoimmune disorder, causing considerable grown of CRP in blood serum, slight evaluation of CRP in the range of $3-10 \mathrm{mg} / \mathrm{l}$ is connected with inflammatory or non-inflammatory affection of vascular walls [22].

Figure 1 shows, that different in hs-CRP concentration in blood serum in patients with syndrome of lumodynia, lumbar ischialgia and control group were not revealed $(p>0,05)$.

At the same time in patients with lumbar sacral radiculopathy a vivid increase hs-CRP concentration in blood serum in comparison with the control group, as well with groups of patients with lumbodynia and lumbar ischialqia syndromes $(\mathrm{p}<0,03471, \mathrm{p}<0,03024, \mathrm{p}<0,03512$, respectively for each case). The mean increase was $164 \%$ in comparison with control group of healthy people. hs-CRP concentration in blood serum in patients with lumbar sacral radiculopathy in recrudescence stage was equal to $8,85+$ $1,66 \mathrm{mg} / \mathrm{l}$, that was maximum in our investigation. The increase at hs-CRP content in blood serum before revealing the concentrations is characteristic exactly for peripheral vessel disorders. [22, 23, 24].

With careful exclusion of other possible peripheral vascular pathology, the increase of hs-CRP content in patients with LSR significantly exceeded hs-CRP values in group of patients with lumbodynia $(3,50 \pm 1,05 \mathrm{mg} / \mathrm{l}, \mathrm{p}<$ $0,00085)$ and lumbar ischialqia syndromes $(3,80 \pm 1,01 \mathrm{mg} / \mathrm{l}$, $\mathrm{p}<0,00732$ ) (Figure 1).

Table 1. Interleukin-1 $\beta$ Content in Blood Serum of Patients with Different Neurological Syndromes of Lumbar-Sacral Osteochondrosis

\begin{tabular}{llll}
\hline $\begin{array}{l}\text { Investigation } \\
\text { groups }\end{array}$ & $\begin{array}{l}\text { Group I (lumbodynia } \\
\text { syndromes) }\end{array}$ & $\begin{array}{l}\text { Group II (lumboischialqia } \\
\text { syndromes) }\end{array}$ & Group III (LSR syndromes) \\
\cline { 2 - 4 } & $\mathbf{M} \pm \mathbf{S D}(\mathbf{n}=\mathbf{7 5})$ & $\mathbf{M} \pm \mathbf{S D}(\mathbf{n}=\mathbf{7 5})$ & $\mathbf{M} \pm \mathbf{S D}(\mathbf{n}=\mathbf{1 5 0})$ \\
\hline $\mathrm{IL}-1 \beta, \mathrm{pg} / \mathrm{ml}$ & $0,66 \pm 0,08$ & $1,21 \pm 0,48$ & $5,47 \pm 0,37^{* *}$ \\
\hline
\end{tabular}

Note $-* *$ differences are significant between the group of LSR patients and all the rest of groups, $(\mathrm{p}<0,01)$.

Table 1 shows that IL-1 $\beta$ content in the control group corresponds to reference values of the norm for healthy examined subjects, given in the test-system "Bender MedSystem" and agrees with the data of other authors who used either analogous ordinary reagent sets, or sets of other firms $[25,26]$.

This study detected clear expression of IL- $1 \beta$ only in group of patients with LSR syndromes in recrudescence stage, Table 1 demonstrates IL- $1 \beta$ concentration equal to $5,47 \pm 0,37 \mathrm{pg} / \mathrm{ml}$; it was 9 times higher than in the control $(0,58 \pm 0,07),(\mathrm{p}<$ $0,00912)$. In patients with lumbodynia syndromes IL-1 $\beta$ concentration correspondent to $0,66 \pm 0,08 \mathrm{pg} / \mathrm{ml}$, that certainly did not differ from values of the control, and was more than 8 times less, than in LSR patients $(p<0,01)$.

In patients with lumbar ischialgia syndrome IL-1 $\beta$ concentration in blood serum was $1,21 \pm 0,48 \mathrm{pg} / \mathrm{ml}$, that was surely not different from the control and 3,9 times less than in the group of patients with LSR ( $<<0,00653)$.

The determined IL-1 $\beta$ level in patients with LSR correlated with values, characteristic for non-infections inflammatory processes [27, 28, 29].

Endothelin-1 content in blood serum of patients with different neurological syndromes of LSO in recrudescence stage in given in Figure 2.

Figure 2 shows significant increase (more than 3 times) of E-1 content in LSR patients in comparison with the control ( $p$ $<0,00075)$ and groups of patients with other syndromes of LSO - lumbodynia and lumbar ischialgia ( $\mathrm{p}<0,00086, \mathrm{p}<$ 0,00073 , respectively for each case). E-1 concentration in blood serum of examined patients (control group) and groups with lumbodynia and lumbar ischialgia syndromes did not differ statistically $(p>0,05)$. There also was no difference in E-1 content in groups with lumbodynia and lumbar ischialgia $(p>0,05)$.

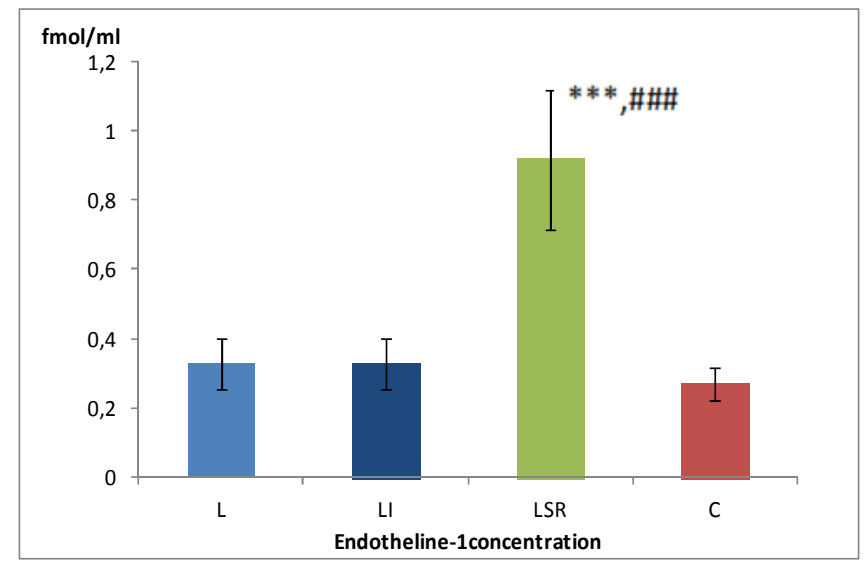

Figure 2. Endotheline-1 concentration ( $\mathrm{fmol} / \mathrm{ml}$ ) in blood serum.

$\mathrm{C}-$ control (IV group), ( $\mathrm{n}=52)$;

$\mathrm{L}$ - patients with lumbodynia syndrome (I group), ( $\mathrm{n}=75)$;

LI - patients with lumbar ischialqia syndromes (II group), $(n=75)$;

LSR-patients with lumbar-sacral radiculopathy syndromes (III group), $(\mathrm{n}=150)$;

Difference are significant between the group of patients with LSR syndromes and the control, $(* * *-\mathrm{p}<0,001)$.

Difference are significant between the group of patients with LSR syndromes and other groups, (\#\#\#- $\mathrm{p}<0,001)$.

It is known that the most part (up to $70-75 \%$ ) of E-1 in secreted by endothelial cells in the directions of smooth muscle cells of a vascular wall and the rest - by smooth muscle cells themselves [30]. Coupling of E-1 with specific receptors on smooth muscle cells membranes results in their contraction, and, therefore, in vasoconstriction - one of the most important mechanisms of peripheral vessel disorders under LSR. The detected increase of E-1 concentration in blood serum in the group of patients with LSR in recrudescence stage confirms that E-1 takes part in the processes of formation of ischemia disorders of peripheral 
blood from under this pathology.

In connections with the fact that CRP and E-1 are factors, causing inductions of adhesion molecules expression either in vitro or in vivo systems [31,32], for further study of endothelin state of peripheral blood stream in patients with neurological syndromes of LSO, we investigated expression of soluble adhesion molecules of vascular endothelium 1 (sVCAM-1) and intercellular adhesion molecules 1 (sICAM-1) with endothelial cells.

These proteins of globulins superfamily are found out in blood serum under different pathology states, accompanied by endothelial disfunction [33, 34]. Results are given in Table 2.

Table 2 demonstrates that recrudescence stage of only one of investigation neurological syndromes of lumbar sacral osteochondrosis - lumbar sacral radiculopathy (LSR) syndromes - is accompanied by increase content of SVCAM-1 and sICAM-1 in peripheral blood serum. Concentration of sICAM-1 really increased by $102 \%$ in comparison with healthy subjects of the control $(\mathrm{p}<0,00645)$, and by $107 \%$ and $53 \%$ in comparison with groups of patients with lumbodynia and lumbar ischialqia syndromes $(p<0,00472$ and $p<0,03615$ respectively for each case).

Table 2. Adhesion Soluble Molecules Content in Blood Serum in Patients with Different Neurological Syndromes of Lumbar-Sacral Osteochondrosis

\begin{tabular}{llll}
\hline $\begin{array}{l}\text { Examined groups/ } \\
\text { Markers of endothelial } \\
\text { disfunction }\end{array}$ & $\begin{array}{l}\text { Group I (lubodynia } \\
\text { syndromes) }\end{array}$ & $\begin{array}{l}\text { Group II (lumboichialqia } \\
\text { syndromes) }\end{array}$ & Group III (LSR sydromes) \\
\cline { 2 - 4 } & $\mathbf{M} \pm$ SD (n= 75) & M \pm SD (n= 75) & M \pm SD (n= 150) \\
\hline sVCAMng/ml & $939,71 \pm 123,22$ & $962,13 \pm 135,21$ & $1864,82 \pm 138,91^{* *}$ \\
sICAM ng/ml & $503,13 \pm 146,92$ & $680,81 \pm 131,54$ & $1043,91 \pm 111,72^{* *}$ \\
\hline
\end{tabular}

Note: **: Differences are significant between the group of LSR patients and all other groups, $(\mathrm{p}<0,01)$.

Concentration sVCAM-1 really increased by $101 \%$ with regard to healthy subjects of the control $(\mathrm{p}<0,00726)$ and by $98 \%$ and $94 \%$ compared to groups with lumbodynia and lumbar ischialqia syndromes ( $\mathrm{p}<0,00748$ and $\mathrm{p}<0,00962$ for each case respectively).

Similar variants of adhesion molecules expression were recorded before in case of CNS damage of vascular etiology, peripheral diabetic neuropathies, diseases of vascular etiology in ophthalmology $[33,34,35,36]$.

Adhesion molecules concentration sVCAM-1 and sICAM-1 in patients with LSR syndromes in recrudescence stage had a clearly seen correlation relationship with factors of proinflammatory process and endothelial disfunction.

So, we detected real correlation relationships of medium force between SICAM-1 concentration and the concentration of hs-CRP $(r=0,44679, p<0,001, n=150)$ ( Figure 3$)$.

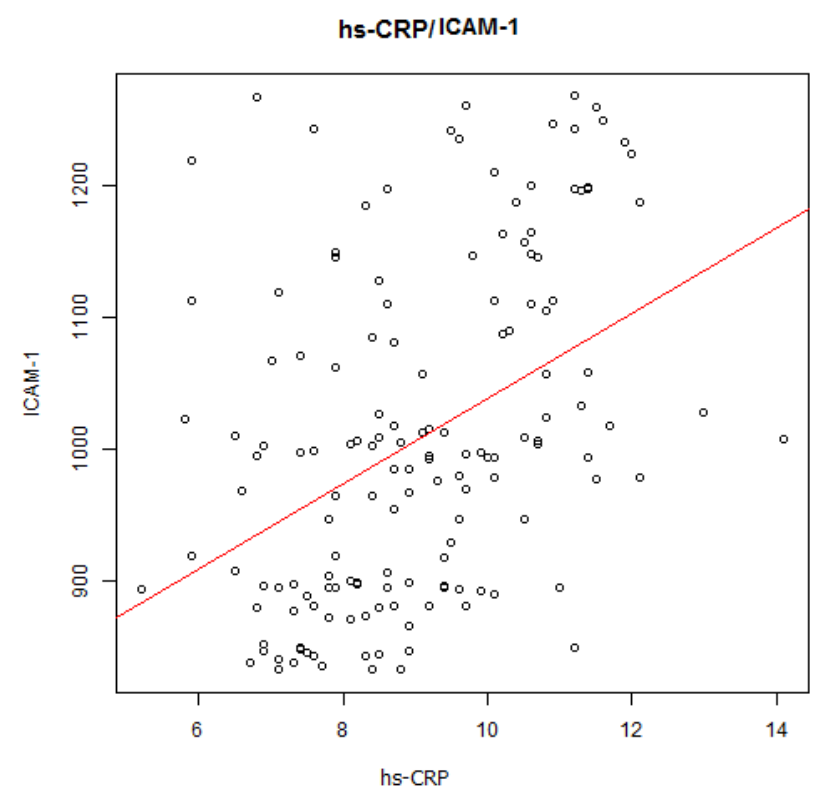

Figure 3. Correlation link between sICAM-1 and hs-CRP
sICAM-1 concentration and the concentration of IL-1 $\beta$ ( $\mathrm{r}=$ $0,25411, \mathrm{p}<0,001, \mathrm{n}=150$ ) (Figure 4)

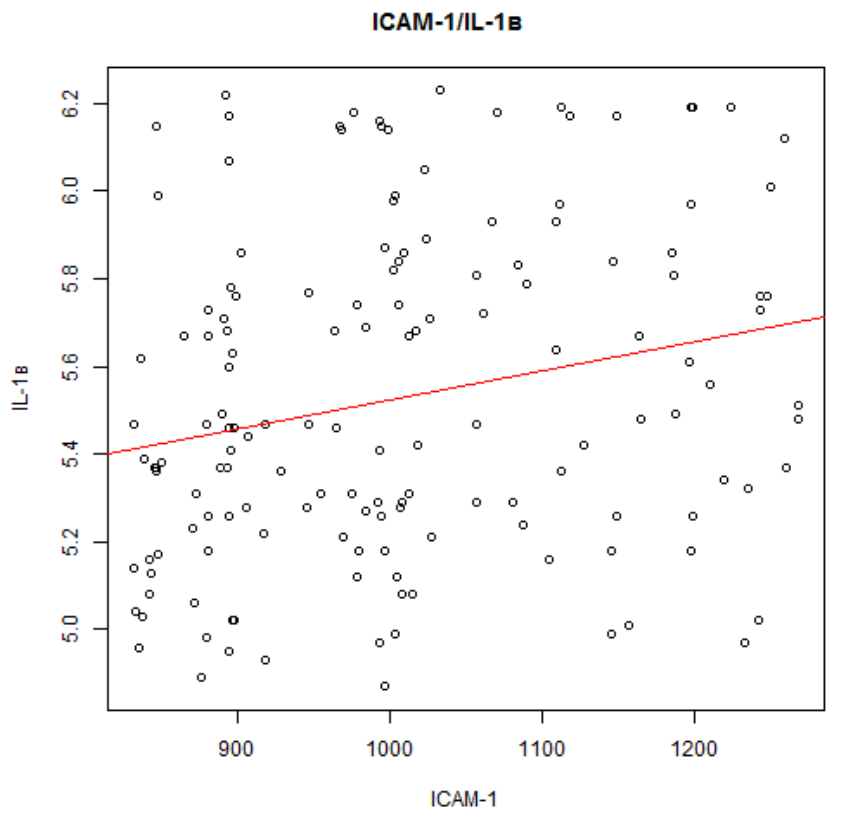

Figure 4. Correlation link between sICAM-1 and IL-1 $\beta$

There is identified real weak correlation relationship between sVCAM-1 concentration and the concentration hs-CRP $(\mathrm{r}=0,17878, \mathrm{p}<0,028, \mathrm{n}=150)$ (Figure 5). 
100 Marina Goryacheva et al.: Biochemical Characteristics of Distal Vessels Endothelium in Patients with Syndroms of Lumbosacral Radiculopathies and others Neurological Syndromes Lumbar Osteochondrosis in Recrudescence Phase

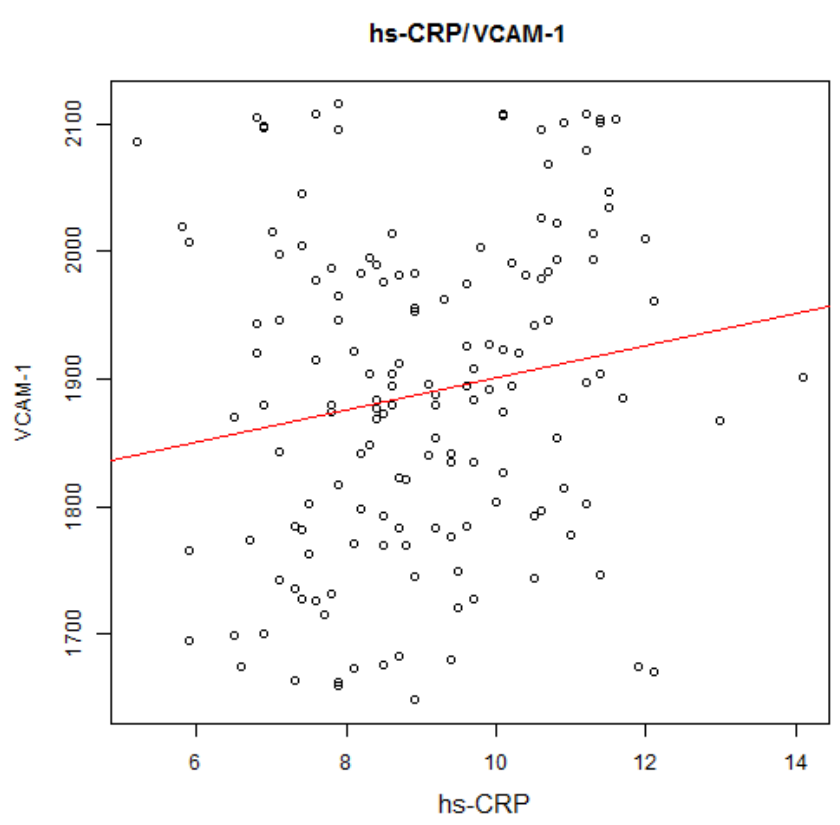

Figure 5. Correlation link between sVCAM-1 and hs-CRP

A strong real one-between SVCAM-1 concentration and the concentration of IL-1 $\beta,(r=0,75955 \mathrm{p}<0,001, \mathrm{n}=150)$ (Figure 6).

VCAM-1/LL-1B

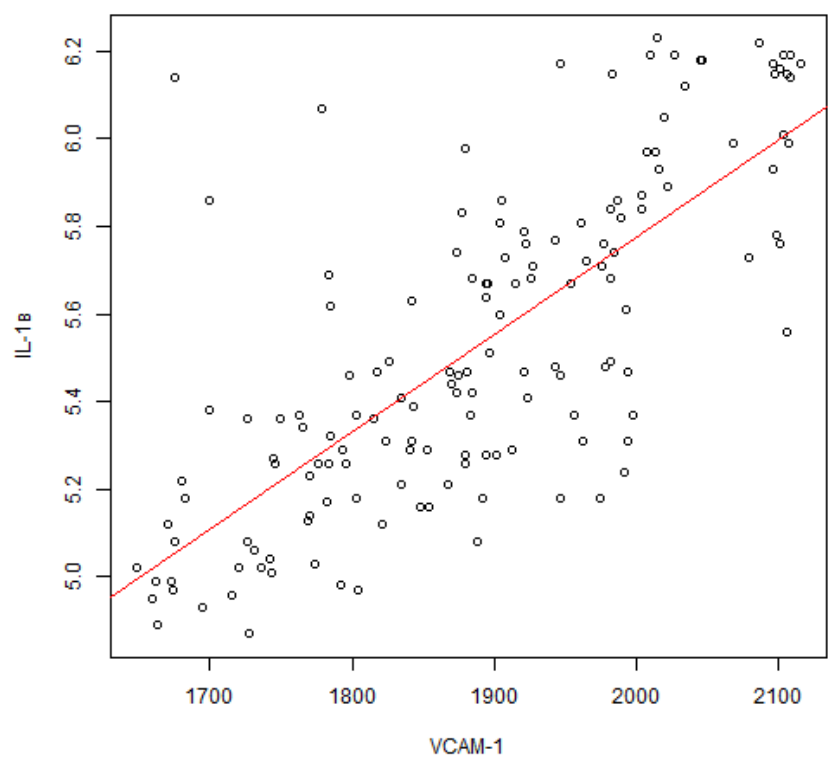

Figure 6. Correlation link between SVCAM-1 and IL-1 $\beta$

In LSR patients in recrudescence stage we determined mean real correlation relationship between the concentration of sICAM-1 and sVCAM-1 and between each other $(r=0,33015$, $\mathrm{p}<0,001, \mathrm{n}=150$ ) in peripheral blood serum (Figure 7).

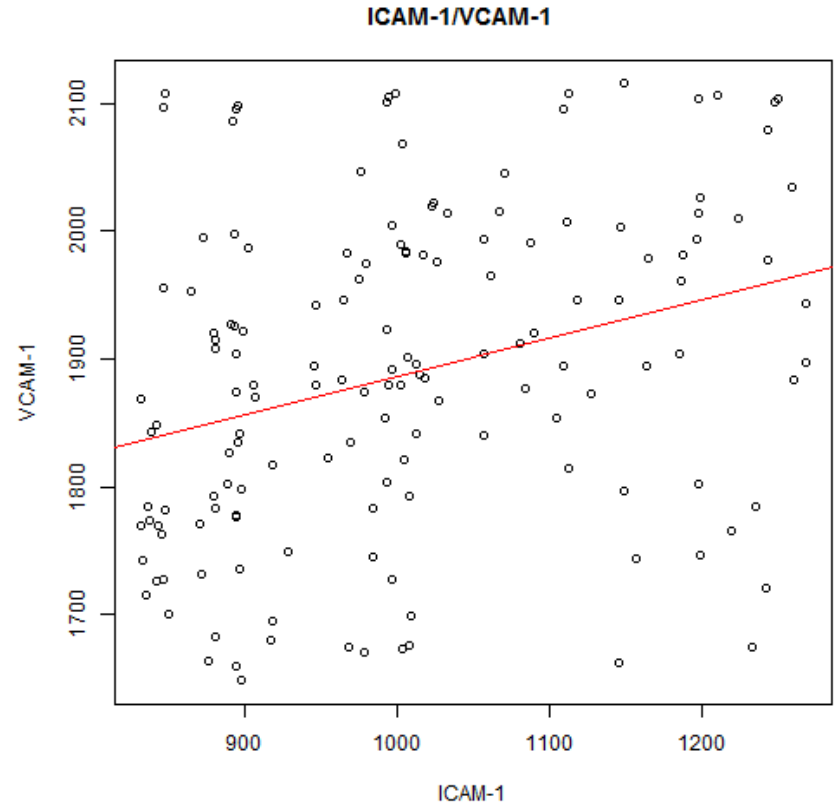

Figure 7. Correlation link between sVCAM-1 and SICAM-1

We also revealed real correlation relationship of mean force between the concentration of sICAM-1 in peripheral blood serum and endothelin-1 concentration, $(r=0,42845, p<0,001$, $\mathrm{n}=150$ ) (Figure 8).

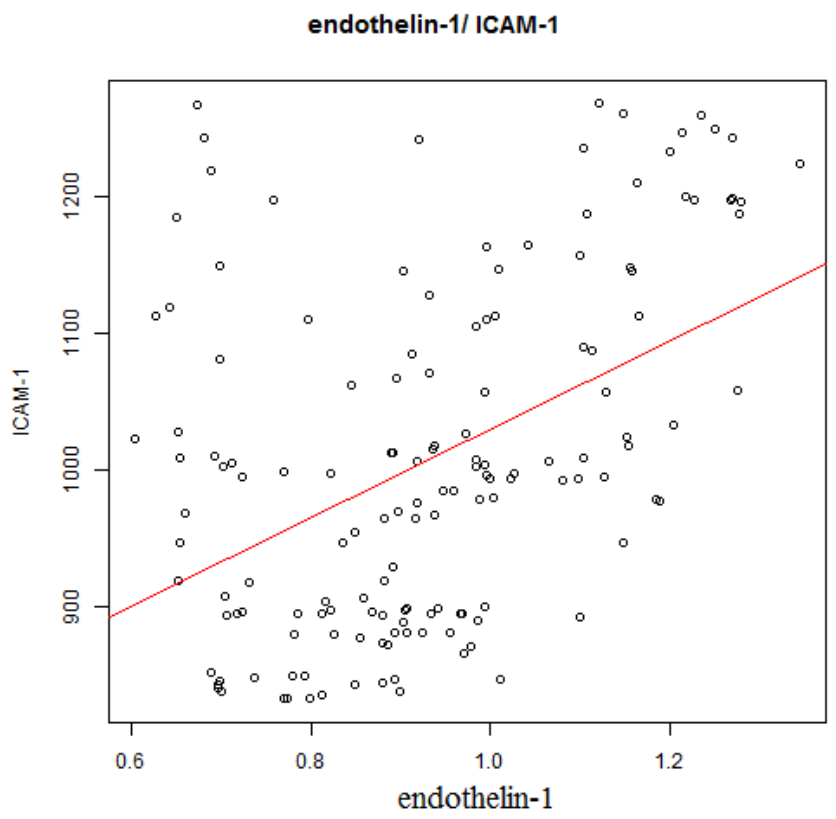

Figure 8. Correlation link between sICAM-1 and endothelin-1

Real weak correlation relationship between sVCAM-1 concentration and that of endothelin-1, $(\mathrm{r}=0,24709, \mathrm{p}<$ $0,0023, \mathrm{n}=150$ ) (Figure 9). 


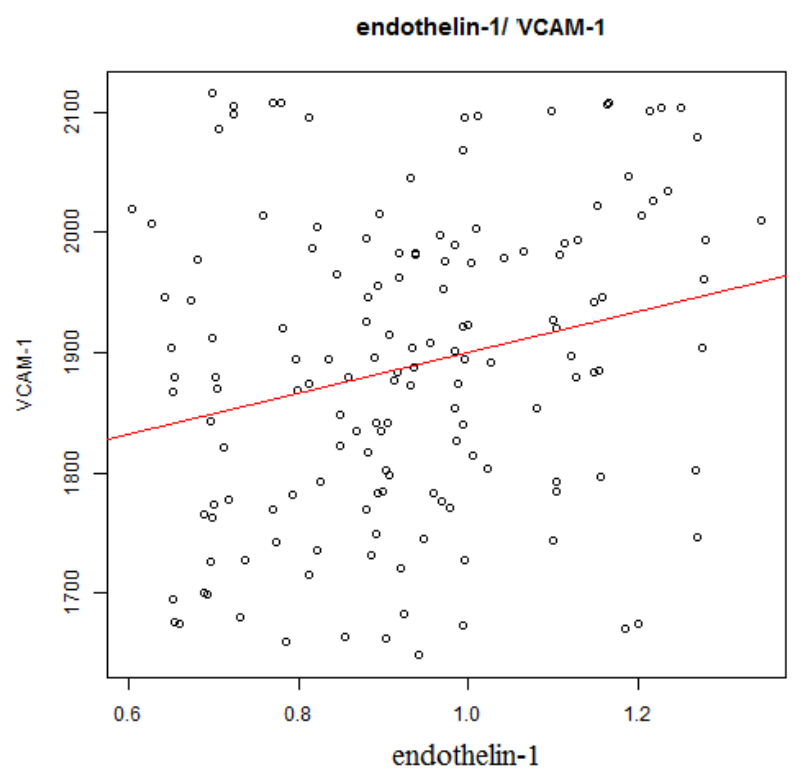

Figure 9. Correlation link between sVCAM-1 and endothelin-1

\section{Conclusion}

Therefore, increased concentration of endothelin-1, soluble adhesion molecules: of vascular endothelium-1 (sVCAM-1) and molecules of intercellular adhesion-1 (sICAM-1), in peripheral blood serum in LSR patients in recrudescence stage, on the background of high concentrations of biochemical factors - markers of proinflammatory processes: hs-CRP and IL-1 $\beta$, speak for the signs of a inflammatory process in peripheral blood stream, accompanied by endothelial cells disfunction. At the same time the absence marked changes of the investigation parameters in blood serum under recrudescence of other neurological LSO syndromes (lumbodynia and lumbar ischialqia) indicate that the pathological process in peripheral vascular wall is a link of pathogenesis and might be one of the main mechanisms of LSR syndromes development in recrudescence phase.

The obtained results confirm the notion about peripheral vascular disorders under LSR as the most important etiological and pathogenetical factors of spondylogenic compression ischemic radiculopathies formation $[7,15,16$, 17]. So it can be concluded, that the pathological process in a peripheral vascular wall is a link of pathogenesis and one of the mechanisms of lumbar-sacral radiculopathy formation.

\section{References}

[1] Low Back pain initiative WHO 1999; 4.

[2] Luo X., Pietrobon R., Sun S. et.al. Estimate and patterns of direct health care expenditures among individuals with back pain in the United States. Spain 2004; 29: $79-86$.

[3] http://www.russianseattle.com/sp/sinalneurology/2_popelyans kiy_in_usa_rus.shtml

[4] http://www.russianseattle.com/sp/sinalneurology/index. shtml
[5] http://www.russianseattle.com/sp/sinalneurology/2_about_my _father_rus.shtml

[6] Popelyansky G.G. Orthopedic Neurology (vertebroneurology): guidance for doctors./ G.G. Popelyansky -Moscow. MEDpress-inform 2003; $670 \mathrm{p}$.

[7] Veselovsky V.P. Practical vertebrology and manual medicine. Riga 1991; 240 p.

[8] Popelyansky Ya. Yu. Diseases of peripheral nervous system. Instructions for physicians doctors. Moscow. MEDpress-inform: Medicine 2005; 386 p.

[9] Kuznetsov V.F. Vertebroneurology: clinic, diagnostic, treatment of spine diseases. Minsk. Book House 2004; 639 p.

[10] Khabirov F.A. Clinical Neurology of Spyne. Kazan 2001; 472 p.

[11] Antonov I.P. Problem of classification and formulation of a diagnose of vertebrogenic (spondylogenic) diseases of nervous system. Peripheral nervous system. Minsk, 1983; p. 49-56.

[12] Veselovsky V.P., Ladygin A.P., Kochergina O.S.. Clinical classification of vertebrological syndromes. Neurology Bulletin. 1995; 27:3-4:45-50.

[13] Zhulev N.M., Badzgaradze Yu.,D., Zhulev S.N.. Spinal osteochondrosis. Instructions for physicians. St. Petersburg. Lan 2001; 592 p.

[14] Klinenko A.V., Kharchenko I.I. Application of non-steroidal anti-inflammatory drugs in complex treatment of myofascial vertebronic syndromes. Ukrainian Bulletin of psychoneurology. 2004; 2: 39: 10 - 11 .

[15] Likhachyova E.B., Sholomov I.I. Clinical-immune evaluation of mexidol effectiveness for lumbar sacral radiculopathy. Neurology and psychiatry journal. 2006; 10: $52-57$.

[16] Belyakov V.V., Sittel A.P., Sharapov I.N., Yeliseev N.P., Gurov Z.P. New outlook on formation of reflexory and compression syndromes of spinal osteochandrosis. Manual Therapy. терапия 2002; 3: 7: 20 - 25.

[17] Novoseltsev S.V. Pathogenic mechanisms of the formathion of lumbar spondilogenic neurologic syndromes in patients with lumbar disk herniae. Manual Therapy. 2010; 3: 39: 77 - 82.

[18] Zaslavsky E.S. Pain muscle syndromes. Novokuznetsk 1981; $12 \mathrm{p}$.

[19] Kruglov V.N., Mokhov D.E. Gainutdinov A.R., Kruglov V.A.. Postural disfunctions in Patients with Lumbar Radicular and Pseudoradicular Syndromes, Osteopathic Correction. Undernational symposium "Functional manual medicine. Theory and Practice". June, 11-13, 2010. Materials . St. Petersburg 2010; p. 145 - 147.

[20] Blagodatsky M.V. Some facts on pathogenesis of caudogenic ambulant lameness syndrome. Neurology and psychiatry journal. 1982; 82: 4: $52-57$.

[21] Ramos A. Lumbar disc herniation: CT imagingassessment and clinical outcome. Eur Radiol 1999; 29 - 36.

[22] Cottone S. Relation of C-reactive protein to oxidative stress and endothelial disfunction in essential hypertension. Hypertension 2005; 23: 2: 58 - 65. 
102 Marina Goryacheva et al.: Biochemical Characteristics of Distal Vessels Endothelium in Patients with Syndroms of Lumbosacral Radiculopathies and others Neurological Syndromes Lumbar Osteochondrosis in Recrudescence Phase

[23] Torzewski M., Rist C., Mortensen R.F., et al. C-reactive protein in the arterial intima: role of C-reactive protein receptor-dependent monocyte recruitment in aterogenesis/ Atheroscler Thromb Vase Biol 2000; 20: 2094 - 2099.

[24] Maksimowicz - McKinnon K., Bhatt D.L., Calabrese L.H. Recent advances in vascular inflammation: $\mathrm{C}$ - reactive protein and other inflammatory biomarkers. Curr Opin Rheum 2004; 16: $18-24$

[25] Jiang A., Wang J., Joshi M., Christoforidis J.B. Systemic Treatments for Noninfectious Vitreous Inflammation. Mediators of Inflammation 2013; Article ID 515312, 11 p.

[26] Wellen K.E., Hotamisligil G.S. Inflammation, stress, and diabetes. Journal of Clinical Investigation 2005; 115: 1111.

[27] Dinarello C.A. Interleukin-1beta and the autoinflammatory diseases. N Engl J Med. 2009; 360: 23: 2467-2470.

[28] Dinarello C.A. Immunological and inflammatory functions of the interleukin-1 family. Annu Rev. Immunol. 2009; 27: $519-550$.

[29] Kastner D.L., Aksentijevich I., Goldbach-Mansky R. Autoinflammatory Disease Reloaded: A Clinical Perspective Cell 2010; 140: 6: 784-790.
[30] Rich S., McLaughlin V.V. Endothelial receptors blockers in cardiovascular disease. Circulation 2003; 108: 2184 - 2190.

[31] Fornoni A., Raij L. Metabolic syndrome and endothelial dysfunction. Current Hypertension Reports 2005; 7: 88 - 95.

[32] Oliveira G.H. Novel serologic markers of cardiovascular risk. Current Atherosclerosis Reports 2005; 7: 148 - 154.

[33] Rich S., . McLaughlin V.V. Endothelial receptors blockers in cardiovascular disease. Circulation 2003; 108: 2184 - 2190.

[34] Teerlink J.R. Endothelins: Pathophysiology and treatment implications in chronic heart failure. Current Heart Failure Reports 2005; 2: $191-197$.

[35] Malik I., Danesh J., Whincup P. et.al. Soluble adhesion molecules andprediction of coronary heart disease: a prospective study and meta-analysis. Lancet 2001; $358: 971-$ 976.

[36] Pasceri V., Willerson J. T., Yeh E.T.H. Direct proinflammatory effect of C-reactive protein on human endothelial cells. Circulation 2000; $102: 2165-2168$. 